\title{
The influence of wind direction on the capture of the wood warbler (Phylloscopus sibilatrix), an uncommon migratory species in the western Mediterranean
}

\author{
Carles Barriocanal • David Montserrat • David Robson
}

Received: 27 November 2010 /Revised: 10 February 2011 / Accepted: 12 February 2011 /Published online: 22 May 2011

(C) The Author(s) 2011. This article is published with open access at Springerlink.com

\begin{abstract}
The wood warbler (Phylloscopus sibilatrix) is a migratory species in the western Mediterranean wintering in the Gulf of Guinea region, West Africa. In autumn and spring, this species, along with the populations breeding in Ireland and Britain, uses the Italian peninsula as its main axis of migration. From the data of captured birds at several ringing stations in the western Mediterranean (Balearic Islands and coastal Iberian Peninsula), we analyzed capture rates of the species during spring migration from 1993 to 2007. Based on the selection of days with a significant number of captures and those without captures, we analyzed the effect of wind direction over the western Mediterranean to determine a relationship between winds and the number of captures. From a total of 663 wood warblers captured between 1993 and 2007, a total of 31 days have been selected as significant days with a high
\end{abstract}

Electronic supplementary material The online version of this article (doi:10.1007/s00484-011-0443-4) contains supplementary material, which is available to authorized users.

C. Barriocanal $(\bowtie)$

Technologies of Geographic Information Technologies

and Environmental Research Group, Department of Geography,

University of Girona,

Plaça Ferrater Mora, 1,

17071 Girona, Spain

e-mail: carles.barriocanal@udg.edu

\section{Montserrat}

Catalonian Forest Fire Prevention Service, Environmental Department, Government of Catalonia. Finca Torreferrussa, 08130 Santa Perpètua de Mogoda,

Barcelona, Spain

C. Barriocanal $\cdot$ D. Robson

Catalan Ornithological Institute (ICO),

Museu de Ciencies Naturals, Passeig Picasso s/n,

08003 Barcelona, Spain number of captures, and 31 days have been selected as nocapture days. On days of maximum captures, winds coming from an easterly direction, i.e. Algeria and Tunisia, were dominant, indicating days with a clear eastern component. Contrary to expected results, captures were also made on days when the wind direction was predominantly from a northerly direction. Analysis of the origin of the winds in north eastern Spain (western Mediterranean) revealed that the majority of northerly winds originated from Africa and not from Europe as is usual for this region. Days or periods selected as no-capture days were characterized by winds coming from a northerly (European origin) or westerly direction.

Keywords Wind direction · Synoptic situation . Mediterranean $\cdot$ Bird migration $\cdot$ Wood warbler

\section{Introduction}

The migration of birds is one of the most prominent phenological events in the natural world with millions of birds moving twice between their breeding and wintering areas during their annual cycle. This migratory journey is characterized by an alternation between the phases of flight, when a bird covers the distance needed to reach the target area by spending energy to get there and phases of stopover, when the bird accumulates energy to continue the flight. The majority of time spent on the migratory journey is spent at stopover areas, whereas the active flight time has been traditionally considered negligible. However, from a theoretical and practical standpoint, potential effects of adverse weather conditions that may affect the cost and timing of migration are important to take into consideration. Factors like temperature, pressure, precipitation, visibility, 
cloud cover and wind conditions have proven to be key to understanding the variations in the onset and speed of migration (Richardson 1990).

Often, the decision to take off is related to current weather conditions, as there is much to be gained by flying with the aid of favorable winds, especially when the birds are faced with the passage of an ecological barrier. For example, studies have shown that passerines take the current wind situation into account when departing on migratory flights and prefer to migrate in tailwinds (Åkesson and Hedenström 2000; Åkesson et al. 2002). Many birds that start to fly over open water return to their departure point, probably due to decreased fuel reserves during nocturnal flights or changed weather conditions (Bruderer and Liechti 1998; Zehnder et al. 2002). The birds that have to cross the Pyrenees in spring en route to their breeding areas in Europe have often found winds with a clear northerly component that can persist for several days and are thus forced to stop and rest until more favorable flight conditions prevail (Barriocanal et al. 2002).

Birds flying actively are fully dependent on prevailing wind direction and speed because of their inability to avoid these winds. In some cases, the wind conditions aloft make it difficult to maintain the right direction and cause significant displacements. If for any reason (strong winds, inexperienced young birds) lateral wind drift cannot be compensated by heading into the wind, it can affect the flight route by causing strong deviations from their goal areas. In the case of small nocturnal passerine migration, being drifted by crosswinds is a real possibility and has been proven to be a likely event when migrating over open seas (Lack 1959; Alerstam and Pettersson 1976).

The wood warbler (Phylloscopus sibilatrix) is a PalearcticAfrican long-distance migrant that breeds in many parts of Europe and winters in the Gulf of Guinea and other parts of tropical Africa. In spring, this species mainly uses a $\mathrm{S}-\mathrm{N}$ direct route to reach their breeding grounds by flying across the Sahara and the Mediterranean while using the Italian peninsula as the main axis of migration in southern Europe. The species appear to follow a clockwise loop migration route, with the northward return journey in spring taking them somewhat farther to the west than their autumn passage (Wernham et al. 2002).

While this species is among the top 10 captured for migration studies in the central Mediterranean, it is captured in relatively smaller numbers in the west (Pilastro et al. 1998). However, on certain days in the spring, the number of these birds flying through small western Mediterranean islands increases several times above average. Our aim is to investigate any meteorological factors that might explain these days of unusual captures of this species in the western Mediterranean region. Specifically, we have studied the effect of the wind, as it is considered to be the main meteorological factor influencing the flight activity of migrant birds (Richardson 1990; Alerstam 1990).

\section{Materials and methods}

From the data of captured birds at several ringing stations in the western Mediterranean (Balearic Islands and coastal Iberian Peninsula) region, we analyzed capture rates of this species during spring migration from 1993 to 2007. Based on the selection of days with a significant number of captures, we have analyzed the effect of wind direction on the framework of these ringing locations as well as the synoptic situation, the general state of the atmosphere which, among others, indicate the direction and intensity of the winds, over the western Mediterranean to determine a relationship between the synoptic situation and days with a high number of captures and days with no captures.

Study area and methods

The study was carried out at five ringing stations spread across the western Mediterranean region (Balearic Islands and coastal Iberian Peninsula; Fig. 1). Further details of study sites are described elsewhere (Barriocanal et al. 2002).

The data obtained form a part of a large-scale project to study spring bird migration through the Mediterranean Sea (Piccole Isole project; see Spina et al. 1993 for details) and was collected during the course of a month from 16 April to 15 May, 1993-2007. This month was the minimum time of operation of the Piccole Isole project and is the period of maximum migration over the western Mediterranean. Although in some locations and in some years the project lasted for more than a month, we restricted the analysis to the period from 16 April to 15 May to make results comparable between years. Columbrets station was not operative in 1993 and Delta de l'Ebre not in 1994 and 1995. Nets were set at fixed sites throughout the entire study period and were open the entire day except during episodes of very bad weather, particularly heavy rain and wind. Each captured bird was ringed, and several biometrical measurements were taken. The number of birds captured was documented, and were tabulated to determine the evolution of captures for the 30 days of the study period each year (Fig. S1). From this table, we selected important peak days on which a large number of captures and no captures were recorded. As a rule, days with a number of captures greater than the standard deviation of the catching rate, which corresponded to those days with greater than 5 captures, were regarded as indicators of a high number of captures. This number was chosen because, above this number, there were significantly fewer days with more 
Fig. 1 The western

Mediterranean showing the locations of the ringing stations used in this study.

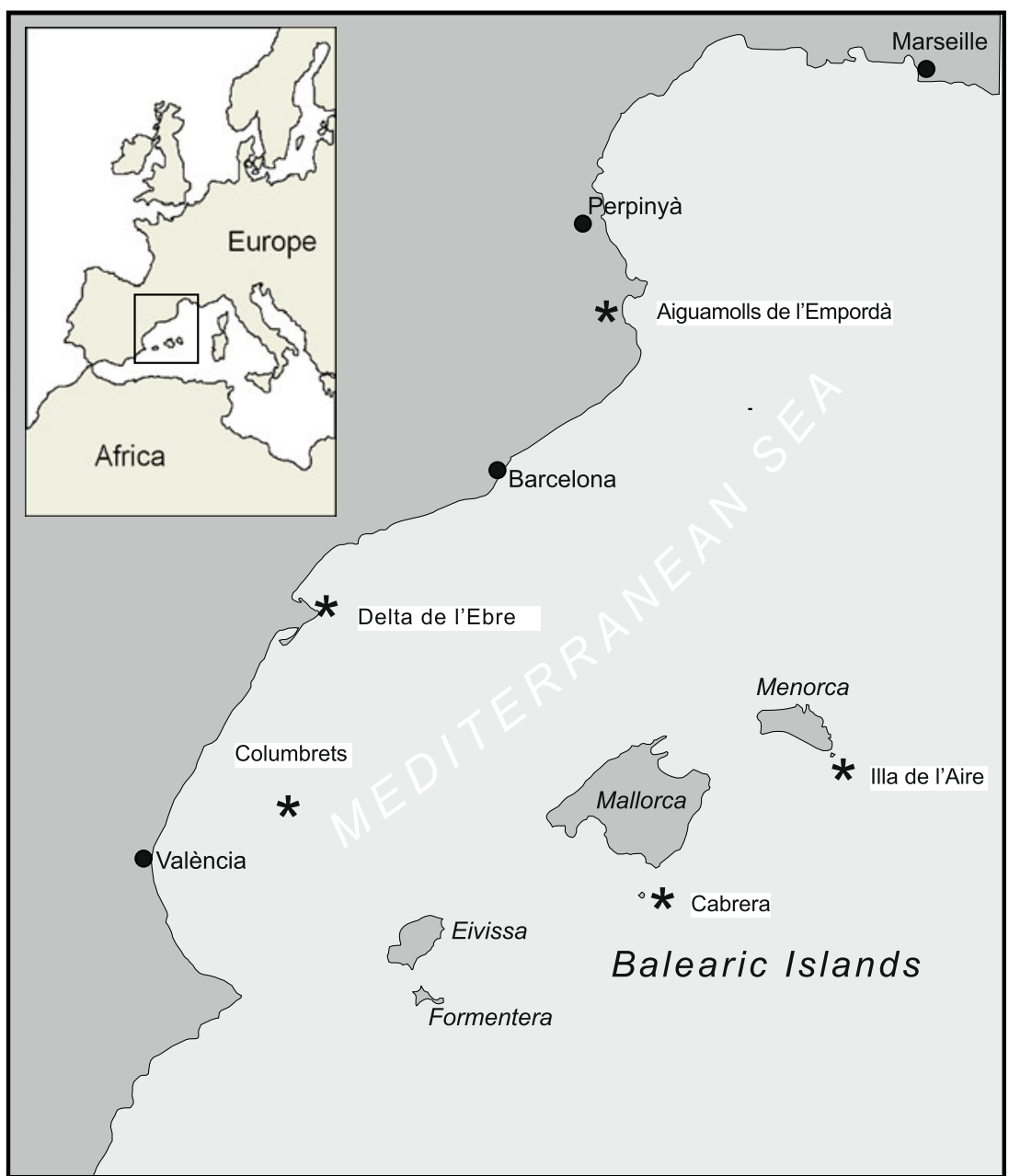

captures (there are many days with fewer captures and a steep drop in days above this number of captures). Therefore, from 450 days of field work, 31 days were selected as having a large number of captures of the wood warbler. Over the same period, days with no captures were selected by taking the central days in three or more consecutive days without a catch. Thus, a total of 31 days without captures was also selected for the analysis. These days are therefore representative of the weather conditions of contiguous runs of several days without a catch. The date analyzed is always the day before capture because it is the most representative of the period during which the bird has been flying.

\section{Wind calculation}

Wind direction at $850 \mathrm{hPa}$ (an approximate height of 1,500 $\mathrm{m}$ ) for the day previous to those selected as maximum captures or the median period without captures was calculated using the $\mathrm{U}$ wind zonal component (W-E) and $\mathrm{V}$ wind meridian component $(\mathrm{N}-\mathrm{S})$ obtained from a timeseries box located over the NE Spain quadrant. These time- series data were obtained from NCEP/DOE Reanalysis from the NOAA database (http://nomad3.ncep.noaa.gov/ ncep_data/). Once the wind direction of the days selected had been calculated, the frequency of days on each component (N, S, W, E) was obtained. One-way ANOVA was used to test for daily capture differences between the four wind components, and post-hoc Tukey tests were used to find the differences between the means of all the groups.

The next step was to analyze the synoptic situation over the western Mediterranean to determine the exact origin of the wind direction.

\section{Synoptic situation}

Using the NCEP/DOE Reanalysis, we obtained the geopotential height at $850 \mathrm{hPa}$ from the four components on a defined grid of $20-60^{\circ} \mathrm{N}, 25^{\circ} \mathrm{W}-45^{\circ} \mathrm{E}$ covering the Mediterranean basin. From these data, we obtained the mean synoptic map of each component. A total of eight maps were obtained: four components from days with high captures and four from those with no capture. 
Table 1 Data of wind direction during the study period over western Mediterranean and of the selected days as high capture and no capture days or periods for wood warbler (Phylloscopus sibilatrix)

\begin{tabular}{llllll}
\hline Wind & No. days & PS_0 & PS_1 & \%PS_0 & \%PS_1 \\
\hline N & 141 & 13 & 9 & 9.2 & 6.4 \\
E & 49 & 2 & 10 & 4.1 & 20.4 \\
S & 101 & 4 & 5 & 4.0 & 5.0 \\
W & 159 & 12 & 7 & 7.5 & 4.4 \\
& 450 & 31 & 31 & 2.8 & 36.1 \\
\hline
\end{tabular}

Wind Main direction of the wind, No. days raw number of days with this main wind direction, $P S \_0$ days without captures of wood warblers, $P S \_1$ days with high captures of wood warblers $(\geq 5), \%$ $P S \_0 \%$ of days without captures of wood warblers, $\% P S \_1 \%$ of days with high captures of wood warblers

\section{Results}

The number of wood warblers caught during the study period was 663, with annual values ranging from 8 in 1993 to 103 in 2006. From the 450 days of fieldwork, 31 days were selected for having a large number of captures. Over the same period, the same number of days without captures was also selected (see "Materials and methods" and Table 1).

The number of daily captures (Table 2) differed significantly across the four components; $F_{3,446}=5.56$, $p=0.001$. Tukey post-hoc comparisons of the four groups indicate that the wind of the eastern component $(\mathrm{M}=3.1$, $95 \%$ CI $2.1,4.1)$ yielded significantly higher daily captures than the southern component $(\mathrm{M}=1.2,95 \%$ CI $0.8,1.6$, $p=0.009$ ). It also provided significantly higher daily captures than the wind of the western component $(\mathrm{M}=0.9,95 \%$ CI 0.7 , $1.2, p=0.001)$. The number of daily captures was also marginally higher than the wind of the northern component $(\mathrm{M}=1.8,95 \%$ CI $0.9,2.6, p=0.09)$. Comparisons between the winds of components $\mathrm{N}, \mathrm{W}$ and $\mathrm{S}$ were not statistically significant $(p>0.6)$.

We found the following synoptic differences (see Tables 1 and 2 and Fig. 2a-d):

a) Winds of the northern component: this was the main wind for 141 out of the 450 days selected (31.3\%).
Fig. 2 a-d Synoptic situation at $850 \mathrm{hPa}$ in the western Mediterranean of the selected periods. The text above each pair of synoptics charts includes the main component of the wind and the $\%$ of days with this wind direction during the capture period of wood warblers. The text box in each pair of charts is the \% of days with and without captures of wood warblers with this component (see "Materials and methods" and Table 1)

Initially, this direction was unfavorable for the migratory flight from Africa because is a headwind and birds try to avoid in order to keep energy undergoing a stopover as stated in previous studies in the region (Barriocanal et al. 2002), but due to the African origin of this component, this synoptic situation was selected by a certain number of wood warblers because this wind from the south (tailwinds) enhanced their migratory flight. The northern component is typically from Europe (Tramuntana) and at southern latitudes we experience intense and cold winds because of their European origin. In our case, the northern wind blows from Africa, making this an exceptional situation. In the Maghreb area, birds found favorable winds (tailwinds), but once in the center of the Mediterranean sea, wind flux turned west due to the low located in Tunisia, and upon arrival at the Iberian peninsula, it became the northern wind that had a barrier effect.

b) Winds of the eastern component: this was the main wind on 49 out of the 450 days selected (10.9\%). This was the prevailing wind for a lower percentage of days during the study period. Strong winds of African origin from this main component match days with a high number of captures. By contrast, with a weak wind speed, the number of captures is very low.

c) Winds of the southern component: this was the main wind on 101 out of the 450 days selected (22.4\%). Strong southern winds of African origin produced many captures. With a local southerly flow of Atlantic origin, few catches were possible.

d) Winds of the western component: this was the main wind on 159 out of the 450 days selected (35.3\%). The prevailing spring wind during the study period was therefore from the west to the northwest. Strong winds

Table 2 Average daily captures of wood warblers, percentage of captures and percentage of each main direction

\begin{tabular}{|c|c|c|c|c|c|}
\hline Wind & Captures/day & No. captures & \%Captures & No. days & $\%$ Direction \\
\hline $\mathrm{N}$ & $1.8(5.3)$ & 247 & 37.3 & 141 & 31.3 \\
\hline $\mathrm{E}$ & $3.1(3.5)$ & 151 & 22.8 & 49 & 10.9 \\
\hline $\mathrm{S}$ & $1.2(2.0)$ & 121 & 18.3 & 101 & 22.4 \\
\hline \multirow[t]{2}{*}{ W } & $0.9(1.6)$ & 144 & 21.7 & 159 & 35.3 \\
\hline & 1.5 & 663 & 100.0 & 450 & 100.0 \\
\hline
\end{tabular}

Captures/day Mean daily number of captures of wood warblers with this main wind direction (with standard deviation), No. captures raw number of captures of wood warblers for each main wind direction, No. days raw number of days with this main wind direction 

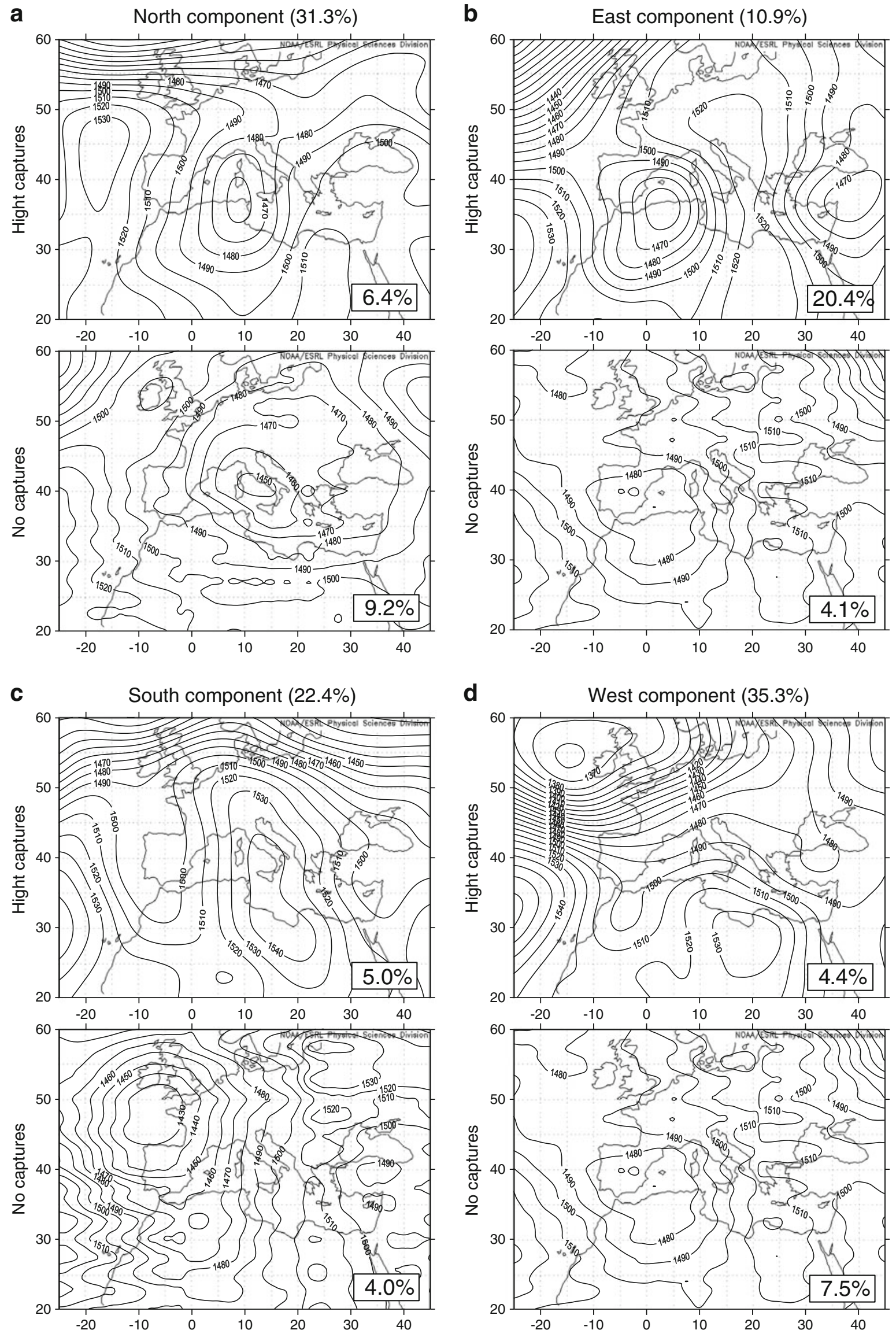
of western Atlantic origin produced low catches. If these winds are weak, then there are some captures.

\section{Discussion}

The wood warbler has a definite spring migration route, flying in a straight S-N direction through the Sahara Desert and the central Mediterranean to arrive at their breeding areas in Europe. While wood warblers are a fairly common migrant in this area, their numbers are very scarce in the western Mediterranean.

However, in the latter area, there are days when the passage of this species is clearly more abundant than in the rest of the migratory season. Our research question focused on whether there are any weather factors that may help explain this pattern of occurrences. Our results show that, on the days of higher catches of this species, winds with a clear flux coming from Algeria and Tunisia were dominant. These days have a clear eastern component over the central Mediterranean, while synoptic situations indicate that in northern Africa winds of the south component predominate. Clearly, our results suggest that during spring migration, this species, while flying through central North Africa with the goal to cross the Mediterranean Sea and arrive at the Italian peninsula, sometimes found good wind conditions (i.e., tailwinds) at departure; however, due to the synoptic situation, the wood warblers found themselves drifting towards the western Mediterranean.

The observed pattern is suggestive of a biological standpoint for two reasons. On the one hand, several studies have found that flight directions at departure correlated with wind directions. It seems that migrating birds prefer to depart during nights with tailwinds suggesting that they try to select favorable wind conditions for their migratory flights (Åkesson and Hedenström 2000; Åkesson et al. 2002). It is therefore likely that days with these conditions show a higher number of departing migrants from North Africa. On the other hand, several studies have shown that, once on their migratory flights, wind drift is a common pattern in passerine nocturnal bird migration (Cochran and Kjos 1985; Liechti 1993; Zehnder et al. 2001; Bäckman and Alerstam 2003), with the exception of species, like the swift (Apus apus), that are particularly efficient (Karlsson et al 2010). In a few cases, it has been observed that small migrants have the capacity to make compensation aloft; the presence of visual landmarks such as rivers or coastlines is necessary for this to happen (Richardson 1991). Therefore, it is likely that small passerines migrating at night over open water have difficulty in maintaining a predetermined heading (cf. Alerstam and Pettersson 1976), and, depending on the weather, they often find themselves displaced from their preferred route. In the case of wood warblers, this would result in some migrants occasionally making a landfall on the islands and the coastline of the western Mediterranean when drifted by strong easterly winds over the central Mediterranean.

Our results show that meteorological conditions, specifically wind conditions, are relevant factors influencing the presence of this species in the western part of the Mediterranean Sea. The usual synoptic pattern in the western Mediterranean does not favor the migration of wood warblers through the central Mediterranean because of the dominating year-long western wind component in this area. However, in some cases, individuals crossing the Mediterranean Sea from Algeria, Tunisia and northern Libya, where a large number of individuals are recorded, found unfavorable winds midway and were forced to change their route from the central region of the Mediterranean to the western Mediterranean.

Further studies may utilize data of birds flying over the Italian peninsula in order to compare their migratory pattern and its relationship with the synoptic situations described here. Also, other species occurring in low numbers in the western Mediterranean (i.e. Icterine Warbler Hippolais icterina) could be studied in order to develop a model of synoptic situations and the presence of central and eastern species.

Acknowledgements We thank Gabriel Gargallo from the Insitute Català d'Ornitologia (ICO) for the access to the data we used. We also thank the two anonymous reviewers who made valuable comments and suggestions on an earlier version of this paper.

Open Access This article is distributed under the terms of the Creative Commons Attribution Noncommercial License which permits any noncommercial use, distribution, and reproduction in any medium, provided the original author(s) and source are credited.

\section{References}

Åkesson S, Hedenström A (2000) Wind selectivity of migratory flight departures in birds. Behav Ecol Sociobiol 47:140 144

Åkesson S, Walinder L, Karlsson L, Ehnbom S (2002) Nocturnal migratory flight initiation in reed warblers Acrocephalus scirpaceus: effect of wind on orientation and timing of migration. $\mathrm{J}$ Avian Biol 33:349-357

Alerstam T (1990) Bird migration. Cambridge University Press, Cambridge

Alerstam T, Pettersson S (1976) Do birds use waves for orientation when migrating across the sea? Nature 259:205-207

Bäckman J, Alerstam T (2003) Orientation scatter of free-flying nocturnal passerine migrants: components and causes. Anim Behav 65:987-996

Barriocanal C, Montserrat D, Robson D (2002) Influences of wind flow on stopover decisions: the case of the reed warbler 
Acrocephalus scirpaceus in the western Mediterranean. Int J Biometeorol 46:192-196

Bruderer B, Liechti F (1998) Flight behaviour of nocturnally migrating birds in coastal areas - crossing or coasting. J Avian Biol 29:499-507

Cochran W, Kjos C (1985) Wind drift and migration of thrushes: a telemetry study. Ill Nat Hist Surv Bull 33:297-330

Karlsson H, Henningsson P, Bäckman J, Hedenström A, Alerstam T (2010) Compensation for wind drift by migrating swifts. Anim Behav 80:399-404

Lack D (1959) Migration across the sea. Ibis 101:374-399

Liechti F (1993) Nächtlicher Vogelzug im Herbst über süddeutschland: Winddrift und Kompensation. J Ornithol 134:373-404

Pilastro A, Macchio S, Massi A, Montemaggioro A, Spina F (1998) Spring migratory routes of eight trans-Saharan passerines through the central and western Mediterranean; results from a network of insular and coastal ringing sites. Ibis 140:591-598
Richardson W (1990) Timing of bird migration in relation to weather: update review. In: Gwinner E (ed) Bird migration. Springer, Berlin, pp 78-101

Richardson W (1991) Wind and orientation of migrating birds: a review. In: Berthold $\mathrm{P}$ (ed) Orientation in birds. Birkhäuser, Basel, pp 226-249

Spina F, Massi A, Montemaggiori A, Baccetti N (1993) Spring migration across central Mediterranean: general results from the "Proggetto Piccole Isole". Volgelwarte 37:1-94

Wernham CV, Toms MP, Marchant JH, Clark JA, Siriwardena GM, Baillie SR (eds) (2002) The migration atlas: movements of the birds of Britain and Ireland. Poyser, London

Zehnder S, Åkesson S, Liechti F, Bruderer B (2001) Nocturnal fall bird migration at Falsterbo, south Sweden. J Avian Biol 32:239-248

Zehnder S, Akesson S, Liechti F, Bruderer B (2002) Observation of free-flying nocturnal migrants at Falsterbo: occurence of reverse flight directions in autumn. Avian Sci 2:103-113 